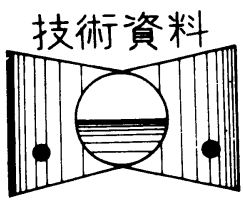

\title{
オイルダンパー内粘性力の振動数 依存性についで
}

葉山眞治**

\author{
Frequency-Dependent Damping Forces \\ in an Oil Damper
}

by Shinji Hayama

It is usually assumed that damping forces in a torsional oil damper are proportional to the relative velocity between the inner and outer rings. This is valid only when the frequencies of the relative velocity are sufficiently low. To express the damping forces correctly at high frequencies, an additional term proportional to the relative acceleration or the relative displacement is necessary, because the phrase lag occurs in the responses of velocity distribution in the narrow passage of the damper. In this paper the frequencydependent viscous forces between the two parallel plates are analyzed, assuming that the one of them oscillates harmonically with a small amplitude in the parallel direction, keeping a small, constant gap, and the added mass and pseudo-stiffness terms are determined.

\section{1. まえがき}

オイルダンパー内流体の粘性力は壁面の相対速度に比 例した減衰力として取扱うのが普通である，ところが， 相対速度の振動数が高くなると，速度に比例した成分の 他に，変位に比例した成分あ生じてくることが実験的に

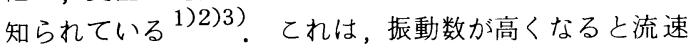
分布の応答に遅れが生じ，壁面せん断力には逆に位相進 みが生じるためである。言替えると，壁面せん断力には 速度に比例した成分の他に，加速度に比例した成分，あ るいは変位に比例した成分が生じるためである。

本報では，平板が粘性流体中で正弦振動を行うとき， この平板に働く壁面せん断力の振動数依存性について考 察し, 付加質量項あるいは見掛けのばね項が生じるとと を示す。

\section{2. 無限流体中で正弦振動をする平板の 壁面せん断力}

現象の物理的意味を明かにするために，始めに無限に 広がった非圧縮性, 粘性流体中で平板がその面内で正弦 振動を行うとき, その片面に㗢く壁面せん断力について

\footnotetext{
*原稿受付 昭和 61 年 10 月 9 日

月例講演会（昭和58年 9 月 2 日）

**正会員 東京大学工学部（東京都文京区本郷 7-3-1）

日本舶用機関学会誌 第 22 巻 第 8 号
}

考える.図 1 に示すように, 静止壁面上に $\mathrm{x}$ 軸, 壁面に 垂直方向に $\mathrm{y}$ 軸をとり, 流れは $\mathrm{x}$ 軸に平行な層流と仮定 すると, 基礎式は次のように表される。

$$
\frac{\partial u}{\partial t}=\nu \frac{\partial^{2} u}{\partial y^{2}}
$$

ここで, $u(y, t)$ は流体の $\mathrm{x}$ 方向速度成分, $\nu$ (二粘 度 $\mu$ /密度 $\rho$ ）は動粘度， $t$ は時間である. 壁面は振幅 $X_{0}$, 角振振動 $\omega$ で, $\mathrm{x}$ 軸に平行に,

$$
X=X_{0} \sin \omega t=R_{e}\left[-i X_{0} e^{i \omega t}\right]
$$

なる正弦振動を行っているとすると, 境界条件は, 流速 振幅を $U\left(=X_{0} \omega\right)$ として, 次のように表される.

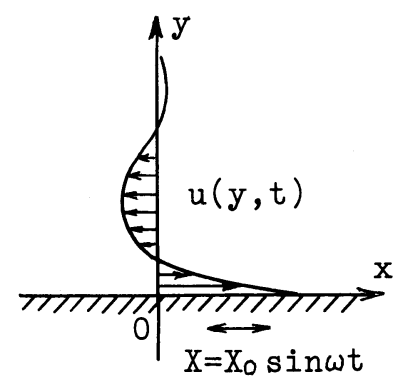

図 1 座標系と境界条件

昭和 62 年 8 月 


$$
\begin{array}{ll}
y=0, & u=\dot{X}=U \cos \omega t=R_{e}\left[U e^{i \omega t}\right] \\
y \rightarrow \infty, & u=0
\end{array}
$$

乙の問題はStokes の第 2 の問題として知られているも ので ${ }^{4)}$,

$$
k=\sqrt{\omega / 2 \nu}
$$

とおくと, 式 (1)の定常解は, 複素表示を用いると,

$$
u(y, t)=U e^{-k y} e^{i(\omega t-k y)}
$$

と表される。式 (5)の実数部が実際の現象を表すあので この速度分布を図 2 に示す ${ }^{* 1}$.



図 2 壁面近傍の速度分布

さて，流体が壁面に与える，単位面積当りのせん断力 を $\tau_{w}$ とすると, $\tau_{w}=\left.\mu(\partial u / \partial y)\right|_{y}=0$ より

$$
\begin{aligned}
\tau_{w} & =-\left(\mu / l^{*}\right)(1+i) k l^{*} U e^{i \omega t} \\
& =-\left(\mu / l^{*}\right)\left(\sqrt{2} k l^{*}\right) U e^{i(\omega t+\pi / 4)}
\end{aligned}
$$

となる。乙こでし*は境界層厚さで, 図 2 の速度分布か ら

$$
\begin{aligned}
& k l^{*} \sim 4 \text { と見れば } \\
& \iota^{*} \sim k / 4
\end{aligned}
$$

である。式(6)を間隔が $l^{*}$ の 2 平行平面の片方が速度 $U \times e^{i \omega t}$ でゆっくり変動する場合の壁面せん断力之比 較すると，実効粘度が $\mu$ より $\mu \sqrt{2} k l^{*} \sim 4 \sqrt{2} \mu$ とな り，位相が $\pi / 4$ だけ進んでいることが分る，位相が進 むのは図 2 の速度分布から分るように，壁面に拈ける速 度勾配が $\omega t=0$ の場合よりあ， $\pi / 4$ 前の $\omega t=-\pi$ /4ときの方が大きくなっているためである。

式（6）は次のように 3 通りに表現するてとができる。

$$
\begin{aligned}
\tau_{w} & =-\left(\mu_{\infty}^{*} / l^{*}\right) \dot{X} \\
& =-\left(\mu_{r}^{*} / l^{*}\right) \dot{X}-m_{\infty}^{*} \ddot{X} \\
& =-\left(\mu_{r}^{*} / l^{*}\right) \dot{X}+\tau_{\infty}^{*} X
\end{aligned}
$$

ここで各係数は次のとおりである。

*1）文献 4) の76頁 Fig. 5.8.に同じ図があるが，ky 軸のスケ ールが間違っているので注意されたい。

$$
\begin{aligned}
& \mu_{\infty}^{*}=\mu(1+i) k l^{*}, \quad \mu_{r}^{*}=\mu k l^{*} \\
& m_{\infty}^{*}=\rho l^{*} / 2\left(k l^{*}\right) \\
& \tau_{\infty}^{*}=2 \rho\left(\nu / l^{*}\right)^{2}\left(k l^{*}\right)^{3} / l^{*}
\end{aligned}
$$

式（ 8 - i ） は複素粘度 $\mu_{\infty}^{*}$ を用いて表すあのである。 式 $(8-\mathrm{ii}) ，(8-\mathrm{iii})$ は位相進みを加速度，あるいは 速度に比例する成分を用いて表すむので， $m_{\infty}^{*}$ は壁面の 単位面積当りの付加質量, $\tau_{\infty}^{*}$ は同じく単位面積当りの 見掛けのばね定数である。乙れらはいずれあ振動数に依 存する値である

\section{3. 平行 2 平面の片方が正弦振動をする 場合の壁面せん断力}

正弦振動をする壁面からしだけ離れた所に静止壁面が ある場合の境界条件は, 式(3)に打いて, $y \rightarrow \infty$ 代わ りに，y=しで $u=0$ とすればよい．乙の場合の解も容 易に求められ，流速分布は次のように表される。

$$
u(y, t)=\frac{\sinh \{(1+i) k(l-y)\}}{\sinh \{(1+i) k \iota\}} U e^{i \omega t}
$$

よって，壁面せん断力は次のようになる。

$$
\tau_{w}=-\frac{\mu}{l}(1+i) k l \operatorname{coth}\{(1+i) k l\} U e^{i \omega t}
$$

ここで，壁面せん断力 $\tau_{w}$ を理解し易い形に書き改める ために，無次元振動数 $k l$ の関数 $H(k l), F(k l)$, $G(k l)$ を次のように定義する。

$$
\begin{aligned}
H(k l) & =(1+i) k l \operatorname{coth}\{(1+i) k l\} \\
& =F(k l)+i G(k l) \\
F(k l) & =\frac{k l\{\sinh (2 k l)+\sin (2 k l)\}}{\cosh (2 k l)-\cos (2 k l)} \\
G(k l) & \left.=\frac{k l\{\sinh (2 k l)-\sin (2 k l)\}}{\cosh (2 k l)-\cos (2 k l)}\right\}
\end{aligned}
$$

このとき，式（11）は次のように表すととができる。

$$
\tau_{w}=-(\mu / l)|H(k l)| U e^{i(\omega t+\phi)}
$$

ここで，位相角 $\phi$ は次式で与えられる。

$$
\begin{aligned}
\phi & =\tan ^{-1}\{G(k l) / F(k l)\} \\
& =\tan ^{-1}\left[\frac{\sinh (2 k l)-\sin (2 k l)}{\sinh (2 k l)+\sin (2 k l)}\right]
\end{aligned}
$$

すなはち，式 (14)は実効粘度が $\mu|H(k l)|$ となり 壁面せん断力は壁面の速度よりもめだけ位相が進むこと を示している。

関数 $H(k l)$ を， $k l$ をパラメータとして複素平面上 にプロットすると，図3のようになる。また，代表的な 值を表 1 に示す

関数 $F(k l), G(k l), H(k l)$ の特徴を知るために, $k l$ が小さ場合の級数展開と $k l$ が大きい場合の漸近展 開を求めると次のようになる。 
$k l \ll 1$ のとき

$$
\left.\begin{array}{l}
F(k l)=1+(4 / 45)(k l)^{4} \cdots \\
G(k l)=(2 / 3)(k l)^{2} \cdots \\
H(k l)=\sqrt{1+(28 / 45)(k l)} \approx 1 \\
\phi=\tan ^{-1}\left\{(2 / 3)(k l)^{2}\right\} \approx(2 / 3)(k l)^{2}
\end{array}\right\}
$$

$k l \gg 1$ のとき

$$
F(k l)=G(k l)=k l
$$

$|H(k l)|=\sqrt{2} k l$

$\phi=\pi / 4$

すなわち，図 3 および表 1 から分るように， $k l \ll 0.5$ であれば $H \approx 1$ であり，位相進みあ小さく定常なクェッ

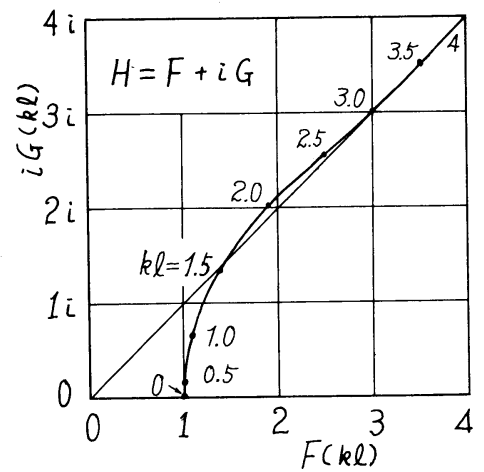

図 3 複素関数 $H(k l)=F(k l)+i G(k l)$

\begin{tabular}{|c|c|c|c|c|}
\hline$k l$ & $F(k l)$ & $G(k l)$ & $|H(k l)|$ & $\phi^{0}$ \\
\hline 0.0 & 1.00000 & 0.00000 & 1.00000 & 0.0 \\
0.1 & 1.00001 & 0.00667 & 1.00003 & 0.38 \\
0.2 & 1.00014 & 0.02667 & 1.00050 & 1.53 \\
0.3 & 1.00072 & 0.05999 & 1.00252 & 3.43 \\
0,4 & 1.00227 & 0.10660 & 1.00793 & 6.07 \\
0.5 & 1.00554 & 0.16640 & 1.01922 & 9.40 \\
0.6 & 1.01146 & 0.23921 & 1.03937 & 13.31 \\
0.7 & 1.02115 & 0.32469 & 1.07153 & 17.64 \\
0.8 & 1.03585 & 0.42230 & 1.11863 & 22.18 \\
0.9 & 1.05690 & 0.53123 & 1.18290 & 26.69 \\
1.0 & 1.08564 & 0.65039 & 1.26555 & 30.93 \\
1.2 & 1.17090 & 0.91335 & 1.48499 & 37.96 \\
1.4 & 1.29829 & 1.19628 & 1.76540 & 42.66 \\
1.6 & 1.46783 & 1.48189 & 2.08579 & 45.27 \\
1.8 & 1.67195 & 1.75488 & 2.42384 & 46.39 \\
2.0 & 1.89781 & 2.00607 & 2.76152 & 46.59 \\
2.5 & 2.47694 & 2.54179 & 3.54908 & 45.74 \\
3.0 & 3.01014 & 3.01849 & 4.26289 & 45.08 \\
3.5 & 3.50901 & 3.50061 & 4.95656 & 44.93 \\
4.0 & 4.00226 & 3.99695 & 5.65630 & 44.96 \\
4.5 & 4.49945 & 4.49853 & 6.36253 & 44.99 \\
5.0 & 4.99937 & 4.99987 & 7.07053 & 45.00 \\
\hline \multicolumn{5}{|c}{}
\end{tabular}

表 1 関数 $F(k l), G(k l),|H(k l)|$ および位相角 $\phi$
ト流れの解と一致する。一方， $k l 》 3$ 程度になると， $H=(1+i) k l$ となり，無限流体中の場合と一致し， 位相進みは $45^{\circ}$ となる。 $k l$ が 2 前後で $45^{\circ}$ よりわずか に大きな位相進みが現れる。 $k l$ が大きいとき, $H$ が $k l$ に比例して大きくなるのは, 境界層厚さが壁面間隔 $l よ$ りあ小さくなって，壁面と共に振動する流体は非常に狭 い範囲に閉じこめられているのと同じ結果になるためで ある。

以上のように，振動数が大きくなるにつれて壁面せん 断力は準定常なクェット流れの場合よりも，その絶対值 が大きくなり，かつ位相進みが生じることが分る。乙れ を準定常なクェット流れとのアナロジーで，速度に比例 する流体力として表現すると複素粘度を用いる必要があ る。たたし，複素粘度といっても物性値である粘度 $\mu$ そ の屯のが複素数になるのではなく，振動数の関数として 壁面せん断力に位相進みが生じることを複素数を用いて 表現したあので, 流体力の一つの表垷法である.

よって，乙の場合屯壁面せん断力は次のように 3 通り に表すことができる．

$$
\begin{aligned}
\tau_{w} & =-\left(\mu^{*} / l\right) \dot{X} \\
& =-\left(\mu_{r} / l\right) \dot{X}-m_{a} \ddot{X} \\
& =-\left(\mu_{r} / l\right) \dot{X}+\tau_{0} X
\end{aligned}
$$

ここで, 記号は次のとおりである

$$
\begin{aligned}
& \mu^{*}=\mu\{F(k l)+i G(k l)\} \\
& \mu_{r}=\mu F(k l) \\
& m_{a}=\rho l G(k l) / 2(k l)^{2} \\
& \tau_{0}=2 \rho(\nu / l)^{2}(k l)^{2} G(k l) / l
\end{aligned}
$$

ここで， $m_{a}$ は壁面の単位面積当りの付加質量であり， $\tau_{0}$ は同じく単位面積当りの見掛けのばね定数である。見掛 けという意味は，乙こで考えている平行壁面間の流れに おいては，むとあと変位に比例する流体力は発生しない のに，てれを変位に比例する流体力として表現したため に，見掛け上現れてきたということである。

\section{4. オイルダンパーへの応用の一例}

粘性ねじりダンパーの内輪と外輪との間の隙間が内輪 の直径に比べて十分小さければ，乙の隙間内の流れは上 記の 2 平行平板間の流れにほぼ等しいと見るととができ る。したがって, 上記の結果は内外輪の相対速度を $\dot{X}$,

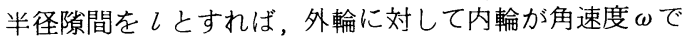
微小なねじり振動を行っている二次元流れのオイルダン パーに直ちに適用することができる。

いま，内輪の直径を $D$ ，半径を $R$ ，ねじり振動成分を $\theta$ とすると,

$$
X=R \theta, \quad \dot{X}=R \dot{\theta}, \quad \ddot{X}=R \ddot{\theta}
$$

であるから, 内輪の端面の影響を無視し, 幅 $b$ の内輪に 働く壁面せん断力の中心軸まわりのトルクを $Q$ とすると $Q=\left(\pi D b \tau_{w}\right) R$ であるから，次式を得る. 


$$
\begin{aligned}
Q & =-C^{*} \dot{\theta} \\
& =-C_{r} \dot{\theta}-I_{a} \ddot{\theta} \\
& =-C_{r} \dot{\theta}+K_{i} \theta
\end{aligned}
$$

(i)

(ii)

(iii)

ここで, $C^{*}, C_{r}, I_{a}, K_{i}$ は次のとおりである。

$$
\begin{aligned}
& C^{*}=\frac{(\pi D b) R^{2} \mu}{l}\{F(k l)+i G(k l)\} \\
& C_{r}=\frac{(\pi D b) R^{2} \mu}{l} F(k l) \\
& I_{a}=\frac{1}{2} \rho(\pi D b l) R^{2} \frac{G(k l)}{(k l)^{2}} \\
& K_{i}=\frac{2 \rho(\pi D b) R^{2}}{l}\left(\frac{\nu}{l}\right)^{2}(k l)^{2} G(k l)
\end{aligned}
$$

である. 式 $(21-i)$ は複素减衰係数 $C^{*}$ を用いるあの, 式 $\left(21\right.$ - ii ) は付加慣性モーメント $I_{a}$ を用いて表す方 法, 式 $\left(21\right.$ - iii ) は見掛りのばね定数 $K_{i}$ を用いて流体 力を表す方法である。

ねじり振動の解を複素数を用いて計算する場合には， どの方法を用いても結局は同じである．強制振動の場合 はあらかじめ角振動数 $\omega$ が与えられるので, 無次元振動 数 $k l$ の関数として $C^{*}, C_{r}, I_{a}, K_{i}$ が定まるので特 に問題は無いが, 自由振動の固有振動数を求める場合は, 角振動数があらかじめ定まっていないので, 估有角振動 数を仮定して繰返し計算を行う必要がある.

\section{5. 結言}

平板が粘性流体中で微小な正弦振動を行う場合の壁面 せん断力を求め，壁面せん断力の振動数依存性について 考察した結果, 次のことが分った。

（1）無限流体中での壁面せん断力は壁面の速度より $45^{\circ}$ 位相が進んでいる。

（2）隙間しを介して静止壁面が有るときの壁面せん断力 は，無次元振動数 $k l(=\sqrt{\omega l / 2 \nu})$ が 0.5 より小さ いときには，準定常なクェット流れの場合と同じになり， またklが 3 より大きくなると，無限流体中の壁面せん 断力と同じになる。

（3）位相進みの効果を記述するには，複素粘度を用いる 方法，付加質量を含む加速度に比例する項で表す方法， および見掛けのばね定数を含む変位に比例する項で表す 方法がある.これらの係数は無次元振動数の関数として 与えられる。

\section{文献}

1) 岩本, Hartmann, R.，舶機誌，17-7 (昭57-7)，520

2) 岩本, 舶機誌, 18-10 (昭58-10)，795.

3）岩本·ほ汃 2 名, 舶機誌, 18-12 (昭58-12)，975.

4) Schlichting, H., Boundary Layer Theory, 4 th Ed., P. 75, Trans by J.Kestin, 1960, Mc GrawHill. 